\title{
PERCEPÇÃO AMBIENTAL DE ALUNOS DE GRADUAÇÃO EM ENGENHARIA SOBRE A IMPORTÂNCIA DA EDUCAÇÃO AMBIENTAL
}

\author{
Erica Leonor Romão ${ }^{1}$ \\ Danúbia Caporusso Bargos² \\ Luiz Allan Garcia da Silva ${ }^{3}$ \\ Letícia Rodrigues de Melo ${ }^{4}$
}

\begin{abstract}
Resumo: O trabalho aqui apresentado buscou avaliar a percepção de alunos de graduação em engenharia de uma instituição pública de ensino superior sobre sua relação com o meio ambiente, experiências e interesses voltados para Educação Ambiental, visando o desenvolvimento de ações e práticas sustentáveis na universidade e na formação de um profissional mais consciente em prol de um desenvolvimento sustentável. Para tanto foi aplicado aos participantes um questionário semiestruturado, cujos resultados permitiram identificar o perfil e o nível de consciência dos alunos sobre as questões ambientais. Em geral, notou-se a predominância de uma visão que considera a Educação Ambiental como uma prática desenvolvida em escolas de ensino fundamental e médio.
\end{abstract}

Palavras-chave: Universidade; Sustentabilidade; Sociedade e Meio Ambiente.

Abstract: The work presented here searched to evaluate the perception of undergraduate engineering students of a public higher education institution about their relationship with the environment, experiences and interests focused on environmental education, aiming at the development of sustainable actions and practices at the university and in the formation of a more conscious professional for sustainable development. To this end, a semi-structured questionnaire was applied to the participants, whose results allowed us to identify the students' profile and level of awareness about environmental issues. In general, there was a predominance of a view that considers Environmental Education as a practice developed in elementary and high schools.

Keywords: University; Sustainability; Society and Environment.

1Universidade de São Paulo. E-mail: ericaromao@usp.br, http://lattes.cnpq.br/3941115051517960

2 Universidade de São Paulo. E-mail: danubiacbargos@usp.br; http://lattes.cnpq.br/1070404228174660

${ }_{3}^{3}$ Universidade de São Paulo. E-mail: luiz.ags@alunos.eel.usp.br; http://lattes.cnpq.br/0725977414980834

${ }^{4}$ Universidade de São Paulo. E-mail: leticia.rodrigues.melo@usp.br; http://lattes.cnpq.br/4302549109360828 


\section{Introdução}

A Educação Ambiental é voltada para a formação e conscientização dos indivíduos sobre os problemas ambientais e a conservação dos recursos naturais. De natureza interdisciplinar ela vem sendo discutida em âmbito global desde a década de 1940 com a criação da Organização das Nações Unidas para a Educação, a Ciência e a Cultura (UNESCO), um órgão da Organização das Nações Unidas (ONU), que iniciou os debates sobre Educação Ambiental na escala global mobilizando governos e entidades da sociedade civil (BARBIERI; SILVA, 2011). Apesar de ter suas origens na década de 1940, as discussões sobre as questões ambientais se tornaram mais efetivas a partir da década de 1970, quando a ONU organizou seu primeiro evento para discussão das questões ambientais no mundo.

A Conferência das Nações Unidas para o Meio Ambiente Humano (CNUMAH), também conhecida como Conferência de Estocolmo, ocorreu em 1972 e teve como um de seus resultados a "Declaração sobre o Ambiente Humano". Trata-se de um documento contendo 26 princípios voltados a preservação e melhoria do meio ambiente humano, com destaque ao princípio 19.

O princípio 19 aponta a necessidade de um esforço global para o desenvolvimento da educação em questões ambientais, considerando a necessidade de a mesma ser voltada para jovens e adultos e que preste a devida atenção ao setor da população menos privilegiado. Neste contexto, a Educação Ambiental possibilitaria a formação de uma opinião pública devidamente informada e a conduta responsável de pessoas, instituições e coletividades para com a proteção e melhoria do meio ambiente em toda a sua dimensão humana (CNUMAH, 1972).

Considerando seus objetivos e resultados, a Conferência de Estocolmo passou a ser considerada um marco inicial para a Educação Ambiental em âmbito internacional. De acordo com Pelicioni (2005, p. 587), nesta Conferência "evidenciou-se a necessidade da educação da população, considerada essencial para ampliar as bases de uma opinião esclarecida e de uma conduta responsável por parte dos indivíduos, empresas e comunidades [...]" considerando a proteção e melhoria do meio ambiente. Foi também a partir da Conferência de Estocolmo que foi criado o Programa das Nações Unidas para o Meio Ambiente (Pnuma), que passou a promover juntamente com a Unesco as discussões de questões relativas à Educação Ambiental no âmbito das Nações Unidas (BARBIERI e SILVA, 2011). Juntas, estas instituições criaram o Programa Internacional de Educação Ambiental (Piea), cujo objetivo foi promover a reflexão e a cooperação entre as nações do mundo para fomentar o desenvolvimento de ações, atividades e pesquisas para melhoria da compreensão e implementação da Educação Ambiental. Nesse intuito, uma das primeiras atividades do Piea foi a realização do Seminário Internacional sobre Educação Ambiental no ano de 1975 na lugoslávia.

Segundo Barbieri e Silva (2011, p.55), 
Uma das primeiras atividades do Piea foi a realização de um Seminário Internacional sobre Educação Ambiental em 1975, no qual foi aprovada a Carta de Belgrado, um importante documento sobre diversas questões pertinentes à $E A$, sob a perspectiva do desenvolvimento sustentável, embora, nessa época, ainda não se usasse essa expressão, a não ser em círculos muito restritos (BARBIERI; SILVA, 2011, p 55).

A Carta de Belgrado apresentou ao mundo os fundamentos para um programa mundial de Educação Ambiental buscando possibilitar 0 desenvolvimento de "novos conhecimento e habilidades, de valores e atitudes, enfim, um esforço direcionado a uma melhor qualidade do ambiente, e de fato, para uma melhor qualidade de vida para as gerações presentes e futuras" (UNESCO, 1975). Nesse documento foram apresentados os seis objetivos da Educação Ambiental, sendo um deles a tomada de consciência sobre o meio ambiente em geral e aos problemas a elas relacionados. Ainda nessa Carta é apresentada como meta da Educação Ambiental a formação de uma população mundial que seja:

[...] consciente e preocupada com o meio ambiente e com os problemas associados, e que tenha conhecimento, aptidão, atitude, motivação e compromisso para trabalhar individual e coletivamente na busca de soluções para os problemas existentes e para prevenir novos (UNESCO, 1975).

Assim, como destinatário principal da Educação Ambiental é colocado o público em geral, considerando num contexto global todos os integrantes da educação formal (alunos desde a pré-escola ao ensino superior, além de professores e profissionais durante sua formação e atualização) e não formal (jovens e adultos, tanto individual como coletivamente, de todos os segmentos da população, tais como famílias, trabalhadores, administradores e todos aqueles que dispõem de poder nas áreas ambientais ou não).

Embora a Carta de Belgrado tenha se configurado como um dos documentos mais importantes até aquele momento em termos conceituais, de princípios e diretrizes associados à educação e àquilo que futuramente viria a ser chamado de desenvolvimento sustentável, a falta de proposições concretas e uma visão pouco realista foram, de acordo com Barbieri e Silva (2011), as críticas mais frequentes ao documento.

De qualquer forma, a Conferência e a Carta de Belgrado serviram de preparatória para aquela que viria a ser considerada a mais importante Conferência Internacional sobre Educação Ambiental: A Conferência de Tbilisi, realizada na Geórgia (Ex-União Soviética), em 1977. Como resultado desta Conferência, foi elaborado um documento final composto por 41 recomendações, onde foram traçados "de forma mais sistemática e com 
abrangência mundial as diretrizes, conceituações e os procedimentos para a Educação Ambiental" (GUIMARAES, 2007).

Dentre as recomendações da Conferência Intergovernamental de Tbilisi sobre Educação Ambiental aos Países Membros, a recomendação no 8 é direcionada aos setores da população aos quais está destinada a Educação Ambiental, sendo:

- A educação do público em geral: todos os grupos de idade e todos os níveis da educação formal, assim como as diversas atividades de educação nãoformal destinada aos jovens e aos adultos.

- A educação de grupos profissionais ou sociais específicos: grupos profissionais cujas atividades e influência tenham repercussões importantes no meio ambiental, como engenheiros, arquitetos, administradores e planejadores industriais, sindicalistas, médicos, políticos e agricultores;

- A formação de determinados grupos de profissionais e cientistas: àqueles que se ocupam de problemas específicos do meio ambiente, tais como biólogos, ecólogos, hidrólogos, toxicólogos, edafólogos, agrônomos, engenheiros, arquitetos, oceanógrafos, limnólogos, meteorologistas, sanitaristas etc.

Outro marco importante na história da Educação Ambiental e das grandes conferências internacionais foi a Conferência das Nações Unidas sobre o Meio Ambiente e de Desenvolvimento Humano, Rio 92, também conhecida como Cúpula da Terra e Eco 92. Durante a Rio 92, foi assinado o Tratado de Educação Ambiental para Sociedades Sustentáveis e Responsabilidade Global - documento que constituiu o marco referencial da Educação Ambiental e evidencia a importância de mobilizar as instituições de ensino superior para atividades voltadas a Educação Ambiental (TRATADO DE EDUCAÇÃO AMBIENTAL PARA SOCIEDADES SUSTENTÁVEIS E RESPONSABILIDADE GLOBAL, 1992).

Desde então, diversas universidades em todo o mundo vêm se articulando para construir suas políticas ambientais, com criação de um órgão institucional para a gestão ambiental, que tem como premissa normalizar questões ambientais a fim de promover a sustentabilidade ambiental dentro de suas áreas; promover o uso racional de recursos; promover um ambiente saudável e construir de forma participativa um modelo de sustentabilidade para a sociedade (BACCl, et al., 2015). Apesar disso, conforme Tauchen e Brandli (2006, p. 505) as primeiras experiências de introdução da temática ambiental nos esquemas de gestão das universidades surgiram nos anos sessenta nos Estados Unidos, "simultaneamente com as promoções de profissionais nas ciências ambientais".

Segundo Disterheft (2012), a universidade sustentável busca envolver o ensino, a pesquisa e a gestão institucional, atuando na redução de energia, emissões, gestão de resíduos e também no ensino sobre sustentabilidade de forma que tanto a comunidade interna quanto a externa possam aprender, 
refletir e praticar de forma consciente novos estilos de vida que levem ao bem estar da atual e futuras gerações.

Uma das formas de promover o interesse de um graduando relacionado ao conhecimento e prática da Educação Ambiental é levá-lo a reflexão e percepção dos conhecimentos já adquiridos, das necessidades de sua profissão e da importância de um aprendizado contínuo para assim tornar-se, não apenas um cidadão, mas também um profissional mais consciente de seu papel na promoção do desenvolvimento sustentável.

A percepção é um processo cognitivo de assimilação de uma informação ou algo presente no ambiente. Esse processo acontece de forma involuntária contribuindo para a conscientização. A percepção ambiental de um indivíduo ou comunidade está diretamente ligada a forma como é apresentada as questões ambientais, de forma a fortalecer a cidadania e a participação da comunidade em questões locais. Assim, atitudes proativas possibilitam a mudanças de paradigmas, de valores e a formação de um novo modelo de desenvolvimento mais consciente (Hammes, 2012, p. 171).

Para Garlet e Canto-Dorow (2011, p. 774) o estudo da percepção ambiental é fundamental para compreensão "das inter-relações entre o homem, o ambiente e suas expectativas, satisfações e insatisfações, julgamentos e condutas". Os mesmos autores consideram também que o conhecimento da percepção ambiental de determinados grupos pode auxiliar a elaboração de ações de conscientização voltadas a realidades locais e regionais distintas. Para autores como Dias (2010) e Garlet e Canto-Dorow (2011) a Educação Ambiental promove os meios de percepção e a compreensão dos distintos fatores que interagem no tempo e espaço modelando o ambiente, representando assim um dos caminhos possíveis para a conscientização. Nesta mesma perspectiva, Guimarães (2007) ressalta, em suas considerações sobre a dimensão ambiental na educação, que a Educação Ambiental é participativa, comunitária, criativa, crítica da realidade vivenciada, formadora da cidadania e transformadora através da construção de novos hábitos e conhecimentos. Assim, se configura como instrumento de sensibilização a conscientização "[...] para as relações integradas ser humano/sociedade/natureza objetivando o equilíbrio local e global, como forma de obtenção da melhoria da qualidade de todos os níveis de vida" (GUIMARÃES, 2007, p. 28)

Para uma mudança de comportamento relativa ao meio ambiente, a percepção ambiental se apresenta como uma ferramenta de análise utilizada para conhecer a forma de pensar e observar das pessoas e assim propor mudanças que possam sensibilizar para uma mudança de atitude. A sensibilização aliada à Educação Ambiental é indispensável para fundamentar os conceitos relativos ao meio ambiente. Conforme Baker (2005) citado Brandalise et al. 2014, a percepção é um processo o qual os estímulos vencem os sentidos, promovendo o início do reconhecimento de informações que levam a interpretação das atitudes através da experiência. 
Conforme Oliveira e Costa (2017, p. 155),

Os indivíduos diferem em sua percepção, e a compreensão da experiência perceptiva varia de indivíduo para indivíduo no tempo e no espaço, tendo motivações individuais as emoções, valores, objetivos, interesses, expectativas e outros estados mentais. Além da variedade de conceitos, há também diversas formas através das quais estudar o assunto, como mapas mentais ou contornos, representações fotográficas e aplicação de questionários (ou formulários)

Considerando o exposto, este trabalho teve como principal objetivo investigar a percepção de graduandos em diferentes engenharias de uma universidade pública do Estado de São Paulo sobre suas experiências e conscientização da importância da Educação Ambiental, visando contribuir para o desenvolvimento de ações e práticas sustentáveis no campus e de uma disciplina a ser oferecida para todos os interessados da unidade.

\section{Metodologia}

A unidade onde o trabalho foi desenvolvido localiza-se em um município da Região Metropolitana do Vale do Paraíba Paulista que tem se destacado pela atuação do poder público nas questões ambientais. A universidade por sua vez tem se empenhado em desenvolver práticas e ações que subsidiem o poder público em suas tomadas de decisão e elaboração de políticas públicas relacionadas ao meio ambiente, que contribuem para formação de profissionais e cidadãos mais responsáveis e conscientes; além de integrar uma rede de universidades sustentáveis.

A metodologia empregada no desenvolvimento do trabalho aqui apresentado pode ser sintetizada em três etapas principais: Pesquisa Bibliográfica, Aplicação de Questionários, Coleta de Dados e Análises Quali Quantitativas.

A pesquisa bibliográfica possui um caráter exploratório e permite definir, a partir da perspectiva científica, o limite da pesquisa que se deseja desenvolver e maior familiaridade com a temática e o problema a ser estudado (DANE, 1990; GIL, 2007). Assim, a pesquisa bibliográfica foi realizada a partir de livros, artigos e teses disponíveis em plataformas digitais buscando a consolidação de um referencial teórico-conceitual que envolve a Educação Ambiental e a avaliação das pessoas sobre sua importância.

Para o levantamento de dados referente à percepção dos alunos dos cursos de graduação em diferentes engenharias sobre a importância da Educação Ambiental foram utilizados como instrumentos questionários estruturados compostos por questões de múltipla escolha e dissertativas. A pesquisa foi restrita e divulgada aos alunos da instituição pesquisada por meio dos canais oficiais de comunicação online dos cursos e redes sociais. 
questionário foi disponibilizado a todos os alunos de seis cursos de graduação em Engenharia da Instituição (total de 98 alunos) no formato online a partir de plataformas digitais gratuitas. O questionário, composto por 10 questões foi dividido em quatro áreas principais: identificação do entrevistado, experiências relacionadas ao desenvolvimento/aplicação/participação em práticas e atividades de Educação Ambiental; nível de conscientização sobre as fases de aprendizado e aplicação da Educação Ambiental; interesse em cursar disciplinas de Educação Ambiental durante o curso de graduação em engenharia.

Buscando a fidedignidade das características do universo em estudo foram considerados a extensão da população alvo, o nível de confiança, o erro máximo permitido e a percentagem de verificação do fenômeno. Para o cálculo da amostra foi realizado o cálculo de tamanho da amostra conforme descrito:

$$
n=\frac{o^{2} \cdot p \cdot q \cdot N}{e^{2}(N-1)+0^{2} \cdot p \cdot q}
$$

Onde:

$\mathrm{n}=$ Tamanho da amostra

02= nível de confiança estabelecido

$\mathrm{p}=$ porcentagem com a qual o fenômeno se verifica

$\mathrm{q}=$ porcentagem complementar $(100-\mathrm{p})$

e= erro máximo permitido

$\mathrm{N}=$ tamanho da população (1985 alunos)

Considerando a população alvo, com erro de $5 \%$ e intervalo de confiança de $95 \%$, o número mínimo representativo para a amostra seria de 92. Para este trabalho obteve-se as respostas de 98 pessoas sendo este um número aceitável e superior em relação ao nível de confiança estabelecido.

Para análise dos dados coletados foi considerada a compatibilidade de abordagens quantitativas e qualitativas, buscando compreender a opinião dos respondentes dos questionários (PALMA, 2005).

\section{Resultados e discussão}

A pesquisa sobre Educação Ambiental foi realizada em abril de 2018 com participação de 98 estudantes de graduação de uma universidade pública do Estado de São Paulo. Os participantes responderam a um questionário composto por questões dissertativas e de múltipla escolha, sendo possível a seleção de mais de uma resposta para determinadas questões, para melhor compreensão das ações. 


\section{Identificação do entrevistado}

Os entrevistados são alunos dos cursos de Engenharia Ambiental, Bioquímica, Física, Materiais, Produção e Química, estando a maioria dos alunos $50 \%$ numa faixa etária de 18 a 21 anos, seguido por alunos de 22 a 24 anos (35\%); maiores que 25 anos (9\%) e 6\% menores de 18 anos. Esses alunos tiveram seu ingresso na seguinte proporção: $28 \%$ em 2018, $14 \%$ em 2017, 14\% em 2014 e o restante distribuído em pequenas frações até o ano de 2012. Como pode ser visto, a grande maioria dos alunos (91\%) possuem idade menor que 24 anos, sendo considerada uma população jovem.

Sobre a participação dos alunos no questionário para avaliação da percepção ambiental é importante ressaltar que o número de alunos matriculados em cada curso é distinto. Como pode ser visto na Tabela 1, as duas primeiras colunas referem-se ao número de alunos entrevistados, ou seja, aqueles que responderam o questionário. A terceira coluna apresenta 0 número total de alunos matriculados em cada curso enquanto a última referese a porcentagem de alunos que responderam o questionário em função do número de alunos matriculados no curso.

Tabela 1: Relação de alunos por curso

\begin{tabular}{|c|c|c|c|c|}
\hline Cursos & $\begin{array}{l}\mathbf{N}^{\circ} \text { de alunos } \\
\text { entrevistados }\end{array}$ & $\begin{array}{c}\% \text { de } \\
\text { entrevistados }\end{array}$ & $\begin{array}{c}\mathrm{N}^{\circ} \text { alunos } \\
\text { matriculados }\end{array}$ & $\begin{array}{c}\% \text { alunos } \\
\text { matriculados } \\
\text { participantes }\end{array}$ \\
\hline Engenharia Ambiental & 43 & $44 \%$ & 186 & $23 \%$ \\
\hline Engenharia Bioquímica & 5 & $5 \%$ & 193 & $3 \%$ \\
\hline Engenharia de Materiais & 5 & $5 \%$ & 181 & $3 \%$ \\
\hline Engenharia de Produção & 9 & $9 \%$ & 242 & $4 \%$ \\
\hline Engenharia Física & 6 & $6 \%$ & 186 & $3 \%$ \\
\hline Engenharia Química & 30 & $31 \%$ & 997 & $3 \%$ \\
\hline Total & 98 & $100 \%$ & 1985 & \\
\hline
\end{tabular}

Em análise à Tabela 1 nota-se que o número de respondentes do curso de Engenharia Ambiental é maior do que os dos demais cursos, seguido pelo número de respondentes do curso de Engenharia Química que é o curso com o maior número de alunos matriculados na unidade. Em termos percentuais os alunos do curso de Engenharia Ambiental também apresentaram uma maior participação (44\%), enquanto os alunos dos outros cursos, inclusive da Engenharia Química, a participação foi da ordem de 3\%.

A maior participação dos graduandos em Engenharia Ambiental pode ser explicada devido a afinidade da área de formação à temática principal da pesquisa realizada. Essa afinidade está ligada ao perfil do estudante de Engenharia Ambiental que, além da sólida formação das Ciências Exatas e 
Biológicas, tem como tarefa a de prevenir a poluição, tratar os resíduos, avaliar, controlar e minimizar impactos da destruição dos recursos naturais atuando de forma integrada contribuindo ao desenvolvimento sustentável.

\section{Experiências relacionadas ao desenvolvimento, aplicação, participação em práticas e atividades de Educação Ambiental}

Para conhecer a relação do entrevistado com a Educação Ambiental (EA), inicialmente foi questionado sobre seu contato com a EA. Do total de participantes, $47 \%$ responderam que já tiveram algum tipo de experiência e/ou contato enquanto 53\% responderam que não (Figura 1a). Dos que responderam que possuíam algum contato (Figura 1b), a maioria respondeu que esse contato ocorreu durante o período de formação escolar, sendo $20 \%$ ensino fundamental, $17 \%$ no ensino médio, $24 \%$ na graduação, outros $11 \%$ dos entrevistados reportaram experiências em outras condições ou situações não sendo possível identificá-las com exatidão, como por exemplo: "Gostei bastante, foi muito esclarecedor"; "participei de aulas e palestras a respeito de conscientização e conservação ambiental entre outros assuntos relacionados"; "tive contato com Educação Ambiental em sala de aula, na forma de aula bem como em projetos"; "Eu nasci e fui criado na serra da Cantareira. Sempre tive contato com a natureza e sempre me foi mostrado a sua importância, e consequentemente a necessidade de preservá-la".

Já teve algum contato com Educação Ambiental (EA)?

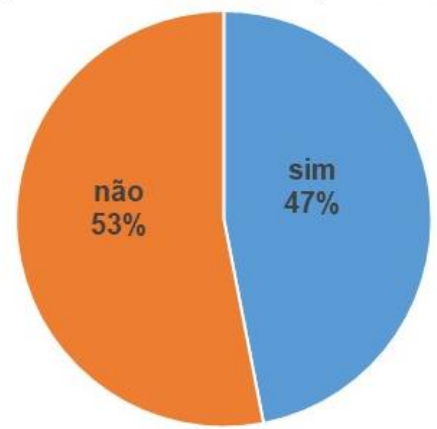

(a)

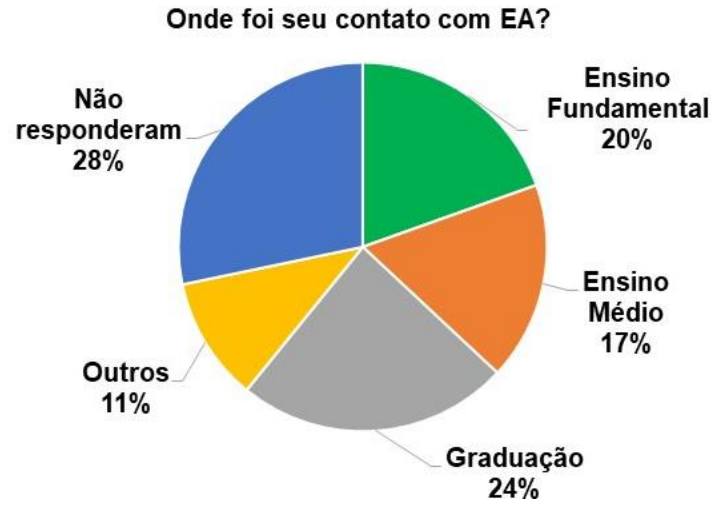

(b)

Figura 1: Contato dos entrevistados com Educação Ambiental. Fonte: Autoria própria (2018).

Dos participantes que declararam ter experiências anteriores com EA foram apontados como principais temas resíduo, água e como principais atividades realizadas participação em projetos, palestras, feira de ciências, e visitas. Em geral, nota-se que a maioria dos participantes reporta temas e atividades amplamente discutidos e desenvolvidos no âmbito escolar, no contexto de disciplinas como Ciências, Biologia e Geografia. 


\section{Nível de conscientização sobre as fases de aprendizado e aplicação da Educação Ambiental}

Para identificação do nível de conscientização sobre as fases de aprendizado e aplicação da Educação Ambiental, foi perguntado aos participantes qual a relação de alguns temas com o conceito de Educação Ambiental (Figura 2). Para esta questão o participante poderia selecionar mais de uma opção como resposta. Os temas apresentados foram selecionados pelos pesquisadores considerando os temas clássicos abordados nas atividades de EA nas escolas como água, lixo e ar (PAGNOCCHESCHI, 1993) e também os temas abordados por Pompeia ( $\mathrm{s} / \mathrm{d}$ ) no vídeo "Grandes temas da atualidade" (POMPEIA; MUHRINGER s/d), tais como mudança climática e discussões sobre aquecimento global; sustentabilidade e biodiversidade visando mostrar a importância da Amazônia; globalização, fontes de energia, autoconhecimento, economia e o meio ambiente, usos da água, consumismo e gestão de resíduos sólidos.

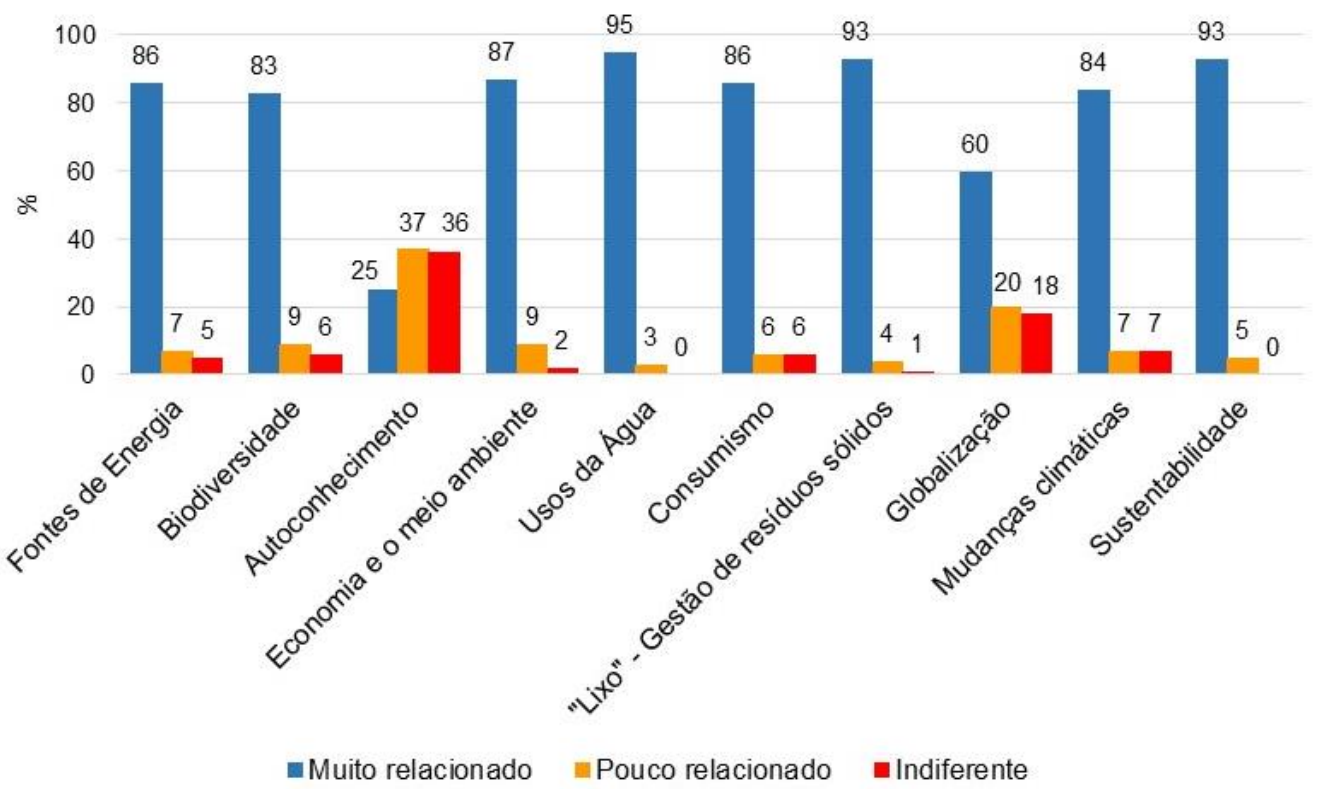

Figura 2: Relação de temas com a Educação Ambiental. Fonte: Autoria própria (2018).

Como pode ser visto, a maioria dos temas listados foram considerados pelos entrevistados como "muito relacionado" com a Educação Ambiental, com valores acima de $83 \%$; exceto o tema autoconhecimento considerado "muito relacionado" a Educação Ambiental por apenas 25\% dos participantes. Os temas autoconhecimento e globalização foram os que os participantes mais consideraram como "pouco relacionado", ou como um tema "indiferente" a Educação Ambiental. Em relação a opinião sobre o tema autoconhecimento, tal postura se deve, provavelmente, o fato do entrevistado não considerar o homem como parte integrante do meio ambiente. De acordo com Santos (2017, p. 142) "há uma contradição que supera as visões de meio ambiente e a inclusão do homem como parte desse meio. A dualidade encontra-se entre a percepção naturalista dos estudantes e a inclusão do homem como integrante 
do meio ambiente". Hammes (2012) ressalta que essa dualidade se repete com frequência em trabalhos sobre percepção ambiental e que, em geral, se reconhece a dependência dos fatores ambientais para a manutenção da vida humana. Nesta perspectiva, Jacobi (2003), orienta que as atividades de EA devem buscar uma visão holística, que relaciona o homem, a natureza e o universo, com conteúdo voltado a conservação do meio ambiente para que o indivíduo perceba que está inserido dentro de sua comunidade e que suas ações interferem e modificam a sociedade. Assim, é importante a realização de trabalhos de Educação Ambiental para conscientização da relação do homem como parte integrante no meio ambiente independente da faixa etária ou nível educacional. Segundo Disterheft (2012), a prática de ações sustentáveis dentro da universidade leva o aluno a aprender e refletir sobre suas ações, fortalecendo seu potencial transformador para atuação junto a comunidade.

Buscando a reflexão dos participantes da pesquisa sobre o seu nível de conhecimento sobre Educação Ambiental foi solicitado aos entrevistados sugestões de outros temas a serem abordados em práticas de Educação Ambiental, dos quais apenas $15 \%$ responderam apontando temas como: agronegócio, desastres naturais, consumo doméstico e desperdícios, alimentação focando na forma como são produzidos e seus impactos e desigualdade social. Considerando as sugestões apresentadas, pode-se notar que os jovens estão atentos a outras problemáticas não tão usuais como resíduos ou água, mas que também afetam tanto a saúde como o meio ambiente.

Outra pergunta apresentada aos participantes foi "Em quais momentos você considera importante aprender sobre EA?", sendo possível mais de uma ou todas as opções apresentadas como resposta. As respostas mais indicadas consideraram o âmbito escolar, no Ensino fundamental e médio, com 93 e 88 respostas, respectivamente (Figura 3). Além destes, outras plataformas também foram selecionados por mais da metade dos participantes, como televisão/vídeos $(72,4 \%)$ e redes sociais $(68,4 \%)$. Na indicação de outros, foram apontados: "em uma disciplina optativa na universidade, sempre, nas ruas e pré-escola".

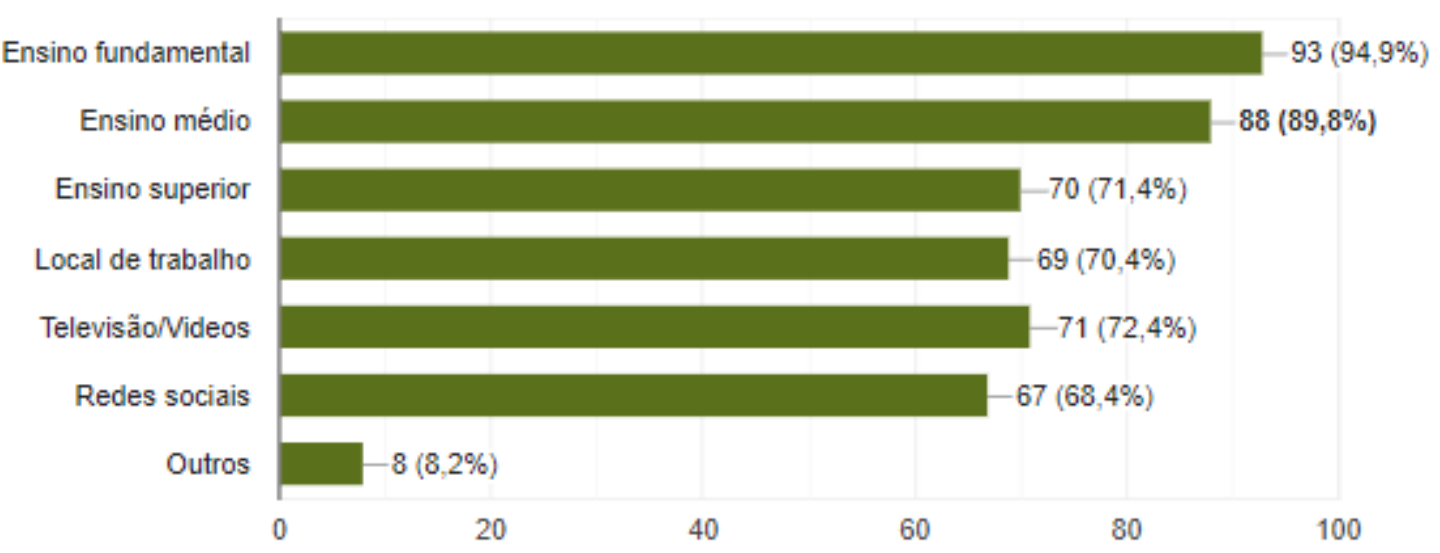

Figura 3: Indicação dos momentos que o entrevistado considera importante APRENDER sobre EA. Fonte: Autoria própria (2018). 
Na sequência, os participantes foram questionados sobre os locais mais indicados para aprender EA. Os entrevistados indicaram locais que poderiam ser aplicados conceitos de Educação Ambiental em todas as opções sugeridas. Mais de $93 \%$ indicou nas escolas e comunidade, $86 \%$ marcaram as opções de aplicar EA em casa, na indústria e no local de trabalho. Na opção outros, foram indicados locais como, "festivais e encontros culturais", "conversa entre amigos", e "toda hora é hora se houver abertura" (Figura 4).

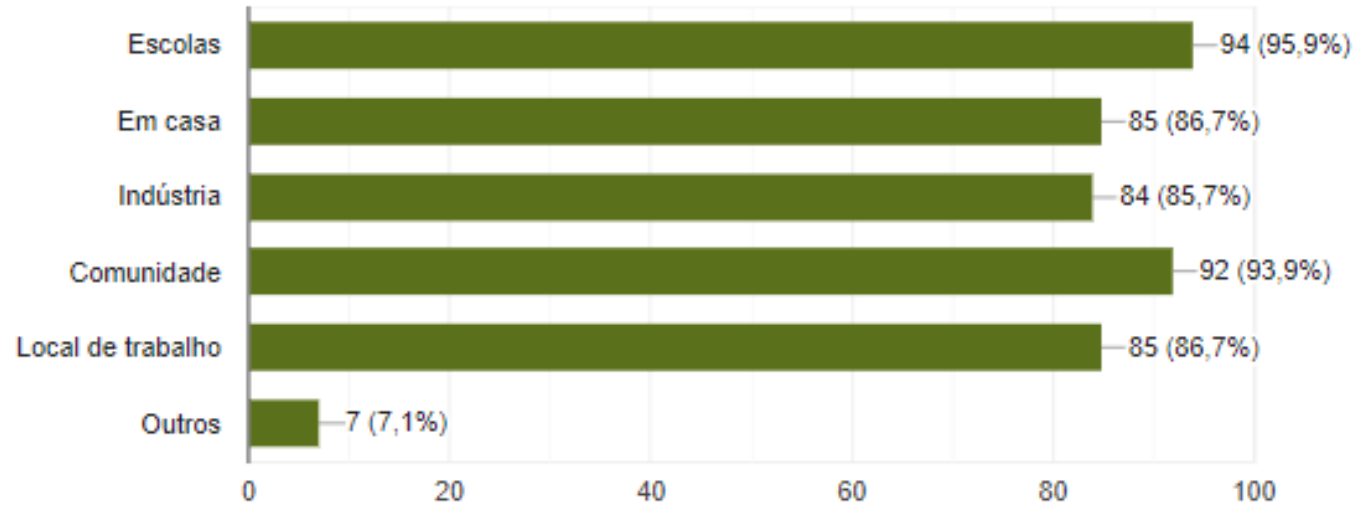

Figura 4: Locais em que o entrevistado APLICARIA os conceitos de EA.

Fonte: Autoria própria (2018).

\section{Interesse em cursar disciplina de Educação Ambiental}

Buscando alinhar os conhecimentos com o interesse de aprofundamento da temática que envolve a EA em sua formação, foi perguntado aos entrevistados o interesse em cursar, durante o curso de graduação em engenharia, uma disciplina de EA como disciplina obrigatória ou optativa (Figura 5).

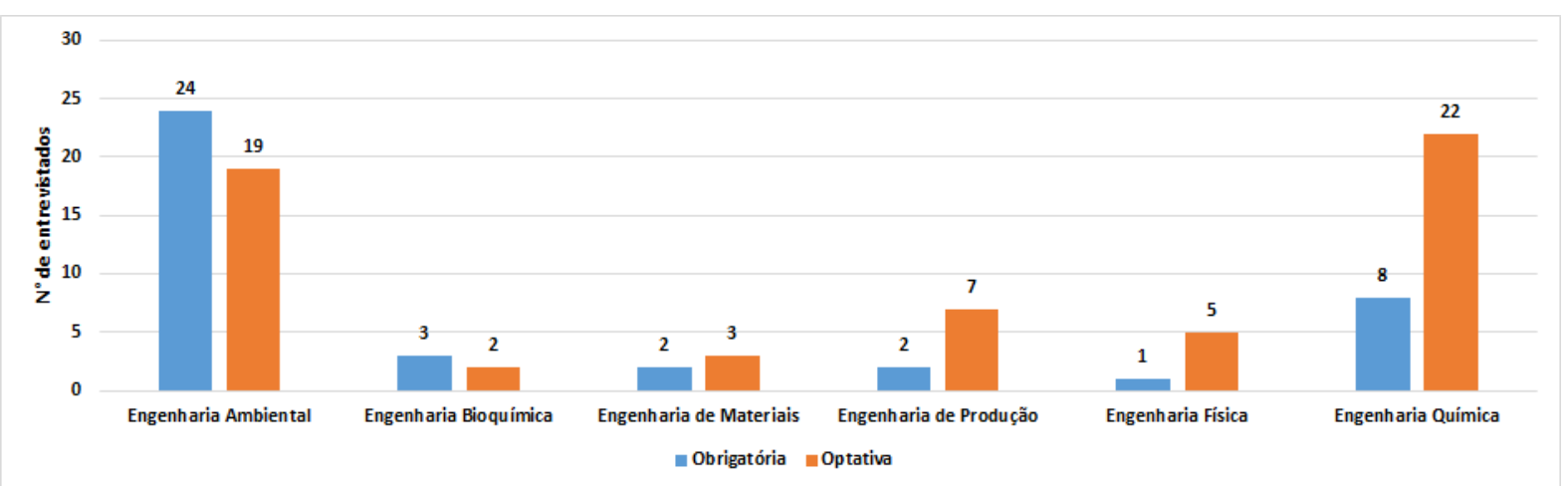

Figura 5: Gostaria de cursar a disciplina de EA como obrigatória ou optativa?

Fonte: Autoria própria (2018).

Em análise às respostas obtidas, é possível notar que a maioria dos alunos do curso de Engenharia Ambiental (55\%) indicou interesse em cursar uma disciplina de EA como obrigatória; enquanto a maioria dos alunos dos demais cursos prefere ter a possibilidade de cursar uma disciplina voltada a EA como optativa. Na totalidade, $59 \%$ dos alunos preferem cursar a disciplina de EA como optativa e $41 \%$ como obrigatória. 


\section{Conclusões}

A Educação Ambiental é considerada um importante instrumento para sensibilizar e conscientizar a sociedade sobre a importância da preservação da natureza e do desenvolvimento de ações e práticas que visam estimular a mudança de hábitos e a compreensão das inter-relações entre o homem e a natureza. A universidade, enquanto promotora da formação profissional, deve buscar a formação de profissionais cada vez mais responsáveis e conscientes de seu papel na proteção do meio ambiente e competentes para busca de soluções dos problemas ambientais.

Os resultados do estudo aqui apresentado permitiram identificar o perfil e o nível de consciência dos alunos sobre as questões ambientais. Possibilitaram constatar também a predominância de uma visão que considera a Educação Ambiental como uma prática desenvolvida em escolas de ensino fundamental e médio, muitas vezes relacionada apenas ao conteúdo das disciplinas de Ciências, Biologia e Geografia, tornando-se assim distante da rotina profissional de um engenheiro. Com exceção dos alunos do curso de Engenharia Ambiental, essa visão se comprova quando a maioria dos entrevistados demonstra maior interesse em cursar uma disciplina de Educação Ambiental, durante o seu curso de Graduação, na modalidade optativa.

De maneira geral, considera-se que as opiniões e percepções dos participantes do estudo são importantes para orientar as ações e práticas sustentáveis a serem realizadas no ambiente universitário. Ações essas que podem ser incorporadas em atividades de uma disciplina optativa de Educação Ambiental a fim de proporcionar conhecimentos específicos relacionados às questões ambientais e estimular nos alunos o desenvolvimento de atitudes e valores com o meio ambiente e com a sociedade em que integra, seguindo a Política Nacional do Meio Ambiente - Lei $n^{\circ}$ 6938/81, que preconiza que a Educação Ambiental deve ser desenvolvida em "todos os níveis de ensino, inclusive a educação da comunidade, objetivando capacitá-la para participação ativa na defesa do meio ambiente".

\section{Referências}

BACCI, D. L. C.; SILVA, R. L. F.; SORRENTINO, M.; Educação Ambiental e Universidade: Diagnóstico Disciplinar para Construção de Uma Política Ambiental. Anais do VIII Encontro Pesquisa em Educação Ambiental - EPEA, Rio de Janeiro, 2015. 4p.

BARBIERI, J.C.; SILVA, D. Desenvolvimento sustentável e Educação Ambiental: uma trajetória comum com muitos desafios. Revista de Administração Mackenzie (Online), v.12, $n^{\circ} 3$, Jun. 2011.

BRANDALISE L. T.; SILVA, J. M. DA; RIBEIRO, I.; BERTOLINI, G. R. F. O reflexo da disciplina de Educação Ambiental na percepção e conduta dos universitários. Pretexto, v. 15, n.4, p 11-26, Belo Horizonte, Outubro 2014. 
CNUMAH. Declaração de Estocolmo sobre o ambiente humano. Estocolmo, 1972. Disponível em: <https://cetesb.sp.gov.br/proclima/wp-content/uploads/ sites/36/2013/12/estocolmo mma.pdf>. Acesso em: 9 set. 2019.

DANE, F. Research methods. Brooks/Cole Publishing Company: California, 1990.

DIAS, G. F. Educação Ambiental: princípios e prática. São Paulo: Gaia Editora, 2010.

DISTERHEFT, A.; CAEIRO, S. S. F. S.; RAMOS, M. R.; AZEITEIRO, U. M. M. Environmental Management Systems (EMS) implementation processes and practices in European higher education institutions - Top-down versus participatory approaches. Journal of Cleaner Production, v.31, p. 80-90, 2012.

GARLET, J.; CANTO-DOROW, J.S. Percepção Ambiental de Alunos do Ensino Fundamental no Município de Nova Palma, RS. Revista Monografias Ambientais, v.4, n4, p. 773-785, Out. 2011.

GIL, A. Como elaborar projetos de pesquisa. Atlas: São Paulo, 2007.

GUIMARÃES, M. A dimensão ambiental na educação. Campinas. Papyrus Editora, 2007.

HAMMES, V. S. Proposta metodológica de macroeducação. Brasília, Embrapa, 2012. 338p.

JACOBI, P. Educação Ambiental, cidadania e sustentabilidade. Cadernos de pesquisa, $n^{\circ}$ 118, São Paulo, p. 189-205, Mar. 2003.

OLIVEIRA, I.G.; COSTA, S. M. F. Análise da percepção ambiental dos moradores de área de várzea urbana de uma pequena cidade do estuário do rio Amazonas. Paisagem e Ambiente: Ensaios. São Paulo, n40, p. 151-167, Dez. 2017.

PALMA, I. R. Análise da percepção ambiental como instrumento ao planejamento da Educação Ambiental. Dissertação de Mestrado em Engenharia. Universidade Federal do Rio Grande do SUL. Porto Alegre, 2005. $27 p$.

PAGNOCCHESCHI, B. EDUCAÇÃO AMBIENTAL: Experiências e Perspectivas. Série Documental EDUCCACIONAIS: Relatos de Pesquisa, n.2C, dez./1993. 35p.

PELICIONI, M.C.F. Educação Ambiental: Evolução e Conceitos. In: PHILIPPI JR (Org.). Saneamento, Saúde e Ambiente: Fundamentos para um desenvolvimento Sustentável. Barueri, Editora Manole, 2005.

POMPÉIA, S. M; MUHRINGER, S. Coleção Educação Ambiental na Escolas: Grandes Temas. Midia DVD-R. Produção: ATTA Midia e Educacao Ltda. s/d. 
SANTOS, A. M.; LOPES, E. R. N. JUNIOR, M. F. S. Percepção Ambiental de Estudantes do Ensino Técnico Federal em Agropecuária e a Contribuição da Educação Ambiental na Formação Profissional. Revista Brasileira de Educação Ambiental. São Paulo, V. 12, No 2: 136-155, 2017.

TAUCHEN, J.; BRANDILI, L. L. A gestão ambiental em instituições de ensino superior: modelo para implantação em campus universitário. Gestão \& Produção, v.13, n.3, p.503-515, Set.-Dez. 2006.

TRATADO DE EDUCAÇÃO AMBIENTAL PARA SOCIEDADES SUSTENTÁVEIS E RESPONSABILIDADE GLOBAL, 1992. Disponível em: < https://www.mma.gov.br/informma/item/8068-tratado-de-educa\%C3\%A7\%C3\% A3o-ambiental-para-sociedades-sustent\%C3\%A1veis-e-responsabilidadeglobal.html>. Acesso em: 26 ago. 2019.

UNESCO. Carta de Belgrado: Uma estrutura global para a Educação Ambiental. 1975. Disponível em <http://www.fzb.rs.gov.br/upload/ 20130508155641carta de belgrado.pdf>. Acesso em: 7 out. 2019. 